\title{
Formation and Mechanical Properties of Porous Pd-Pt-Cu-P Bulk Glassy Alloys
}

\author{
Takeshi Wada $^{1, *}$, Kana Takenaka ${ }^{1, *}$, Nobuyuki Nishiyama ${ }^{2}$ and Akihisa Inoue ${ }^{3}$ \\ ${ }^{1}$ Department of Materials Science, Graduate School of Engineering, Tohoku University, Sendai 980-8577, Japan \\ ${ }^{2}$ RIMCOF Tohoku Univ. Lab., R\&D Institute of Metals and Composites for Future Industries, Sendai 980-8577, Japan \\ ${ }^{3}$ Institute for Materials Research, Tohoku University, Sendai 980-8577, Japan
}

Porous $\mathrm{Pd}_{35} \mathrm{Pt}_{15} \mathrm{Cu}_{30} \mathrm{P}_{20}$ bulk glassy alloy rods were prepared by holding the alloy melts under $1 \mathrm{MPa}$ hydrogen atmosphere, followed by water quenching in reduced hydrogen pressures of 0.9 or $0.1 \mathrm{MPa}$. The volume fraction and size of pores were controlled by hydrogen pressure of the atmosphere. No crystalline phase was observed over the whole pore wall regions. The porous alloys show slightly decreased thermal stability as compared with the pore-free one, but still keep a large supercooled liquid region. The porous alloy rods exhibited significant plastic elongations in compression while the pore-free rod fractured instantly after the elastic strain limit. The high plasticity of the porous alloys is presumed to originate from the generation of a high density of shear-bands resulting from the effect of stress concentration around the pores.

(Received June 20, 2005; Accepted August 30, 2005; Published December 15, 2005)

Keywords: porous bulk glassy alloy, palladium-based alloy, mechanical property

\section{Introduction}

Porous metallic materials are known to have many interesting combinations of unique mechanical, chemical, thermal and acoustic properties. ${ }^{1,2)}$ Consequently, they have been applied as structural materials, shock absorption materials, sound absorption materials, filter materials and so on. ${ }^{2,3)}$ Recently, biocompatible porous metallic materials were developed for $\mathrm{Ti}$ and $\mathrm{Mg}$ metals by powder metallurgy process. ${ }^{4}$ ) The advantage of these biomedical porous materials is that the mechanical properties can be adjusted by controlling the volume fraction, size and geometry of the pores. That is, the fracture strength and Young's modulus of porous materials can match human bone. ${ }^{1)}$ In addition, their open-pore structure lets the bone-tissues ingrowth and subsequently makes strong bonding with human bone when the size and shape of the pores are appropriate..$^{5,6)}$

On the other hand, bulk glassy alloys such as $\mathrm{Mg}_{-}{ }^{7)}$ $\mathrm{La}-,{ }^{8)} \mathrm{Zr}-,{ }^{9,10)} \mathrm{Cu}-,{ }^{11)} \mathrm{Pd}-,{ }^{12)} \mathrm{Fe}-,{ }^{13)}$ and $\mathrm{Co}^{-}{ }^{14)}$ based alloys are expected to become important candidates for biomedical materials because they exhibits high strength, low Young's modulus and high corrosion resistance simultaneously. ${ }^{15}$ Among these bulk glassy alloy systems, Pd-based bulk glassy alloys have extremely high glass-forming ability (GFA). For instance, some $\mathrm{Pd}-\mathrm{Cu}-\mathrm{Ni}-\mathrm{P}$ bulk glassy alloys can be formed in cylindrical shape with a diameter of larger than $72 \mathrm{~mm}$ by a water quenching technique, ${ }^{16}$ ) which is high enough to make practical parts. Recently, a Ni-free Pd-Pt$\mathrm{Cu}-\mathrm{P}$ bulk glassy alloy with maximum diameters larger than $30 \mathrm{~mm}$ was successfully prepared. ${ }^{17}$ ) The new Pd-based glassy alloy is judged to contain less toxic element in all high GFA alloys reported so far and hence is expected to have better biocompatibility with human body.

Porous bulk glassy alloys have much attention recently because of their useful characteristics which cannot be obtained for pore-free bulk glassy alloys. Close-pore type porous bulk glassy alloys have been developed in $\mathrm{Pd}-\mathrm{Cu}-\mathrm{Ni}-$ $\mathrm{P}$ alloy by $\mathrm{B}_{2} \mathrm{O}_{3}$ hydrate ${ }^{18)}$ or high hydrogen pressure. ${ }^{19,20)}$

*Graduate Student, Tohoku University
Similarly, open-pore type $\mathrm{Pd}-\mathrm{Cu}-\mathrm{Ni}-\mathrm{P}$ and $\mathrm{Zr}-\mathrm{Nb}-\mathrm{Al}-\mathrm{Cu}-$ $\mathrm{Ni}$ porous bulk glassy alloys have been produced by melt infiltration into $\mathrm{NaCl}^{21)}$ or $\mathrm{BaF}_{2}{ }^{22)}$ salt pre-foam. Their features are lower density, lower Young's modulus, higher plasticity and larger surface area. By combining a new Pdbased bulk glassy alloy with these useful features of the porous bulk glassy alloys, we can expect to develop an appropriate biomedical material. This paper intends to present the preparation method, porous structure, thermal stability and mechanical properties of porous bulk glassy Pd$\mathrm{Pt}-\mathrm{Cu}-\mathrm{P}$ alloy rods.

\section{Experimental Procedures}

A Pd-P binary alloy with nominal atomic composition of $\mathrm{Pd}_{60} \mathrm{P}_{40}$ was prepared using pure $\mathrm{Pd}(99.95$ mass $\%)$ and phosphorous (98 mass\%) in a quartz tube at $1323 \mathrm{~K}$. Then, a $\mathrm{Pd}-\mathrm{Pt}-\mathrm{Cu}-\mathrm{P}$ alloy ingot with nominal atomic composition of $\mathrm{Pd}_{35} \mathrm{Pt}_{15} \mathrm{Cu}_{30} \mathrm{P}_{20}$ was produced by arc melting the mixture of $\mathrm{Pd}-\mathrm{P}$ pre-alloy and pure $\mathrm{Pd}, \mathrm{Pt}$ (99.9 mass\%) and $\mathrm{Cu}$ (99.99 mass\%) metals in an argon atmosphere followed by $\mathrm{B}_{2} \mathrm{O}_{3}$ flux treatment. Porous $\mathrm{Pd}_{35} \mathrm{Pt}_{15} \mathrm{Cu}_{30} \mathrm{P}_{20}$ bulk glassy alloys with a diameter of $4 \mathrm{~mm}$ and a length of about $40 \mathrm{~mm}$ were produced by following three processes; (1) holding the molten $\mathrm{Pd}-\mathrm{Pt}-\mathrm{Cu}-\mathrm{P}$ alloy at $1023 \mathrm{~K}$ under $1 \mathrm{MPa}$ hydrogen atmosphere for $2 \mathrm{~h}$ to solve hydrogen uniformly in the alloy melt, (2) reducing hydrogen pressure from $1 \mathrm{MPa}$ to 0.9 or $0.1 \mathrm{MPa}$ to create hydrogen pores, and (3) water quenching the alloy melt to form a glassy alloy containing hydrogen pores. The pore-free $\mathrm{Pd}-\mathrm{Pt}-\mathrm{Cu}-\mathrm{P}$ alloy rod with a diameter of $30 \mathrm{~mm}$ and a length of $50 \mathrm{~mm}$ was also produced by a water quenching technique in a $0.1 \mathrm{MPa}$ argon atmosphere. Glassy structure was examined by X-ray diffractometry (XRD, Rigaku RINT2200). Porous structure was examined by optical microscopy (OM, Olympus $\mathrm{BH}$ ) and scanning electron microscopy (SEM, Hitachi S-800). Thermal stability and crystallization behavior of the supercooled liquid were examined by differential scanning calorimetry (DSC, Seiko Instruments DSC6200) at a heating rate of $0.67 \mathrm{~K} / \mathrm{s}$. Density was measured by an Archimedean method using tetra brome 


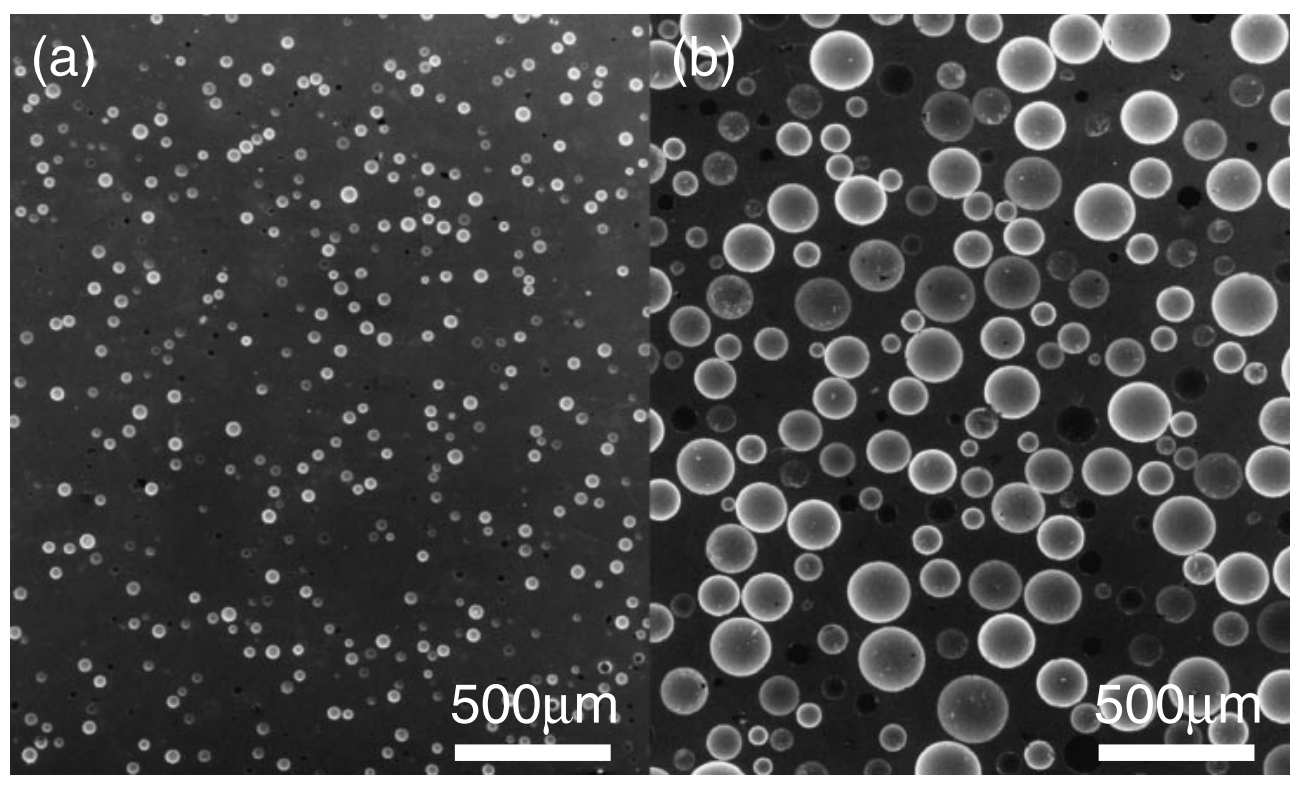

Fig. 1 Transverse cross-section of porous $\mathrm{Pd}_{35} \mathrm{Pt}_{15} \mathrm{Cu}_{30} \mathrm{P}_{20}$ bulk glassy alloys prepared by holding the alloy melt for $2 \mathrm{~h}$ under $1 \mathrm{MPa}$ hydrogen atmosphere followed by water quenching in reduced hydrogen pressure of 0.9 or $0.1 \mathrm{MPa}$; (a) $5 \%$ porosity, (b) $45 \%$ porosity.

ethane. Mechanical properties under a compressive load were measured by a conventional mechanical testing machine (Instron4201). The test specimens had a cylindrical shape with $3 \mathrm{~mm}$ in diameter and the length of $6 \mathrm{~mm}$ and a rectangular shape of $3 \mathrm{~mm}$ in width, $3 \mathrm{~mm}$ in thickness and $6 \mathrm{~mm}$ in height. The initial strain rate was $5 \times 10^{-4} \mathrm{~s}^{-1}$.

\section{Results and Discussion}

Figures 1(a) and (b) shows the transverse cross section of the porous $\mathrm{Pd}_{35} \mathrm{Pt}_{15} \mathrm{Cu}_{30} \mathrm{P}_{20}$ alloy prepared by holding the $\mathrm{Pd}-\mathrm{Pt}-\mathrm{Cu}-\mathrm{P}$ melt at $1023 \mathrm{~K}$ for $2 \mathrm{~h}$ in an $1 \mathrm{MPa}$ hydrogen atmosphere followed by water quenching in reduced hydrogen pressures of 0.9 and $0.1 \mathrm{MPa}$, respectively. One can see spherical pores that are homogeneously dispersed in the whole cross sectional area. It is also confirmed that pore distribution along the longitudinal cross-section is homogeneous over the whole cross-section of the rod specimen with the length of $40 \mathrm{~mm}$. The uniform distribution of the pores is considered to originate from high viscosity of glass-forming alloy liquid. At the liquidus temperature, typical glassforming alloy melt have viscosity of 1 to $10 \mathrm{Pas}$, which is three orders of magnitude higher than normal metallic liquid. ${ }^{23)}$ It is reported for the $\mathrm{H}_{2} \mathrm{O}$ vapor pore in the $\mathrm{Pd}-$ $\mathrm{Cu}-\mathrm{Ni}-\mathrm{P}$ alloy liquid that the velocity of rising pore due to the gravity effect is almost negligible in such a highly viscous liquid. ${ }^{18)}$ The density was measured as $10.64 \mathrm{Mg} / \mathrm{m}^{3}$ for the former porous sample and $6.16 \mathrm{Mg} / \mathrm{m}^{3}$ for the latter sample. Assuming that the sample prepared in $0.1 \mathrm{MPa}$ argon atmosphere contains no pore, their porosities were calculated to be 5 and $45 \%$, respectively. The average pore size is $40 \mu \mathrm{m}$ for the $5 \%$ porosity sample and $200 \mu \mathrm{m}$ for the $45 \%$ porosity sample.

Figure 2 shows XRD patterns of the cross sectional area of the $5 \%$ porosity sample and $45 \%$ porosity sample, together with the data of the pore-free sample. Both XRD patterns consist of only a broad halo peak and no sharp peak

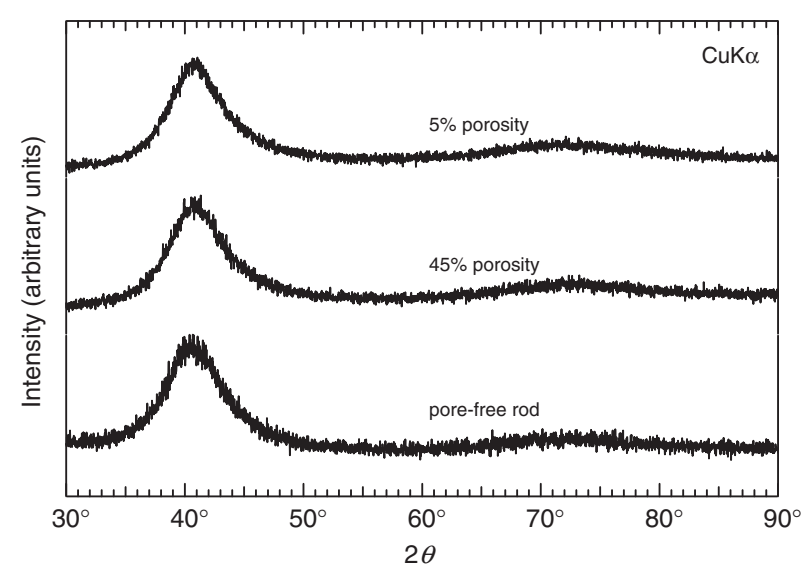

Fig. 2 X-ray diffraction patterns of porous $\mathrm{Pd}_{35} \mathrm{Pt}_{15} \mathrm{Cu}_{30} \mathrm{P}_{20}$ bulk glassy alloys with porosities of 5 and $45 \%$. The data for the pore-free glassy alloy prepared by water quenching in $0.1 \mathrm{MPa}$ argon are shown for comparison.

corresponding to a crystalline phase was observed, indicating that these porous $\mathrm{Pd}-\mathrm{Pt}-\mathrm{Cu}-\mathrm{P}$ alloys were fully composed of a glassy phase.

Figure 3 shows DSC curves of the porous $\mathrm{Pd}-\mathrm{Pt}-\mathrm{Cu}-\mathrm{P}$ alloy quenched from $1023 \mathrm{~K}$ in various hydrogen atmospheres, together with the data of the sample prepared by water quenching in $0.1 \mathrm{MPa}$ argon atmosphere. The feature of the DSC curve of the porous samples is similar to that of the pore-free one; an endothermic reaction due to the glass transition followed by a large supercooled liquid region and an exothermic reaction due to crystallization. The glass transition temperature $\left(T_{\mathrm{g}}\right)$ is $560 \mathrm{~K}$ for all samples and the crystallization temperature $\left(T_{\mathrm{x}}\right)$ is $645 \mathrm{~K}$ for the pore-free sample while the porous samples have slightly lower $T_{\mathrm{x}}$ values, i.e., 640 for the $45 \%$ porosity sample and $630 \mathrm{~K}$ for the $5 \%$ porosity sample. The supercooled liquid region $\left(\Delta T_{\mathrm{x}}=T_{\mathrm{x}}-T_{\mathrm{g}}\right)$ of the porous alloys are $83 \mathrm{~K}$ for the $45 \%$ porosity sample and $72 \mathrm{~K}$ for the $5 \%$ porosity sample, which 


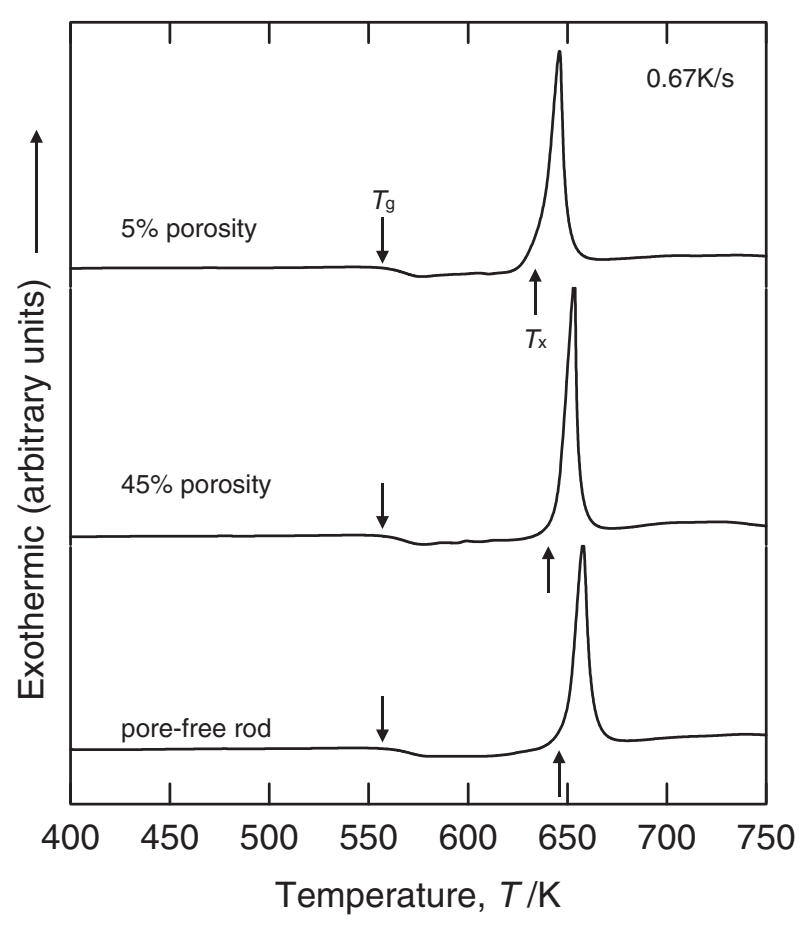

Fig. 3 DSC curves of porous $\mathrm{Pd}_{35} \mathrm{Pt}_{15} \mathrm{Cu}_{30} \mathrm{P}_{20}$ bulk glassy alloys with the porosities of 5 and $45 \%$. The data for the pore-free alloy prepared by water quenching in $0.1 \mathrm{MPa}$ argon are shown for comparison.

are slightly smaller than that $(89 \mathrm{~K})$ for the pore-free alloy. This discrepancy is considered to result from the hydrogen interstitially solving in glassy matrix. However, these porous alloys still have a large supercooled liquid region, indicating that the glassy phase still keeps high thermal stability against crystallization.

Figure 4 shows nominal stress-strain curves of the porous bulk glassy $\mathrm{Pd}-\mathrm{Pt}-\mathrm{Cu}-\mathrm{P}$ alloy, together with the data of the pore free sample. A distinct difference between the porous samples and the pore-free sample can be seen. That is, the

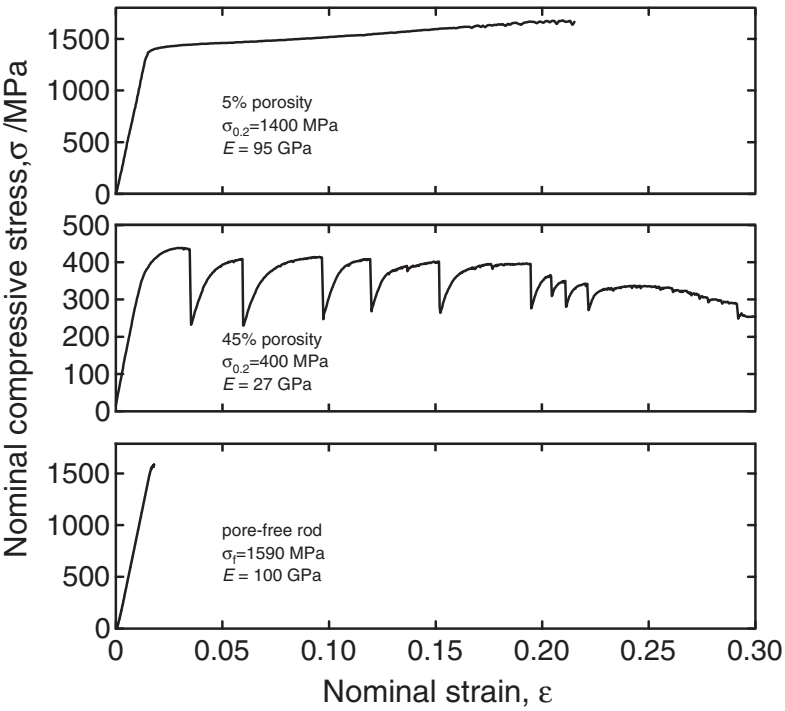

Fig. 4 Compressive stress-strain curves of porous $\mathrm{Pd}_{35} \mathrm{Pt}_{15} \mathrm{Cu}_{30} \mathrm{P}_{20}$ bulk glassy alloys with the porosity of 5 and $45 \%$. The data for pore-free one are shown for comparison.

pore-free rod ruptures instantly after the elastic strain limit, while the porous rods show significant large plastic elongation after the elastic strain. The $0.2 \%$ proof stress $\left(\sigma_{0.2}\right)$, Young's modulus $(E)$, and plastic strain $\left(\varepsilon_{\mathrm{p}}\right)$ are $1400 \mathrm{MPa}$, $95 \mathrm{GPa}$, and 0.2 , respectively for the $5 \%$ porosity sample and $400 \mathrm{MPa}, 27 \mathrm{GPa}$ and $>0.3$, respectively, for the $45 \%$ porosity sample while those of the pore-free rod are $1590 \mathrm{MPa}, 100 \mathrm{GPa}$ and 0 , respectively. Thus, although the fracture strength and Young's modulus of the porous samples decrease, it is noted that plastic strain drastically increases for the porous samples. To understand deformation behavior of the porous samples, SEM observation was carried out for the deformed samples. Figure 5 shows SEM micrographs of the (a) $5 \%$ and (b) $45 \%$ porosity samples subjected to plastic

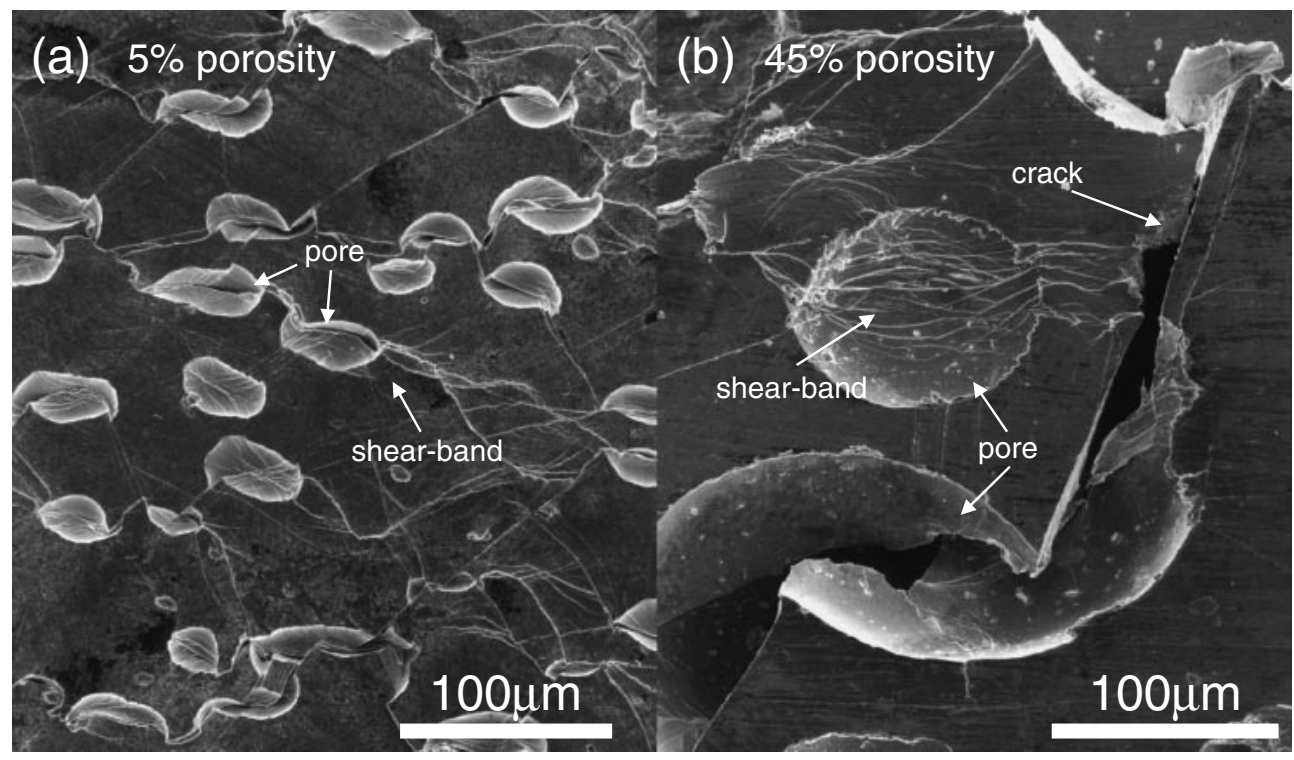

Fig. 5 Scanning electron micrographs revealing the outer surface of porous $\mathrm{Pd}_{35} \mathrm{Pt}_{15} \mathrm{Cu}_{30} \mathrm{P}_{20}$ bulk glassy alloys with the porosities of (a) $5 \%$ and (b) $45 \%$ subjected to the compressive plastic deformation up to 0.2 and 0.05 strain, respectively. 
deformation up to 0.2 and 0.05 strain, respectively. From these fracture morphologies, the high plasticity for the porous rod is considered to be resulted from two factors. One is the generation of multi-axis stress field due to the presence of pores. As reported for the cold-rolled bulk glassy alloy, the multi-axis stress condition causes the multiple generation of shear-band resulting in an increase of plasticity. ${ }^{24)}$ Another is the effect of stress concentration around the pores. A higher applied stress around the pore is forced to introduce shearbands or cracks. In Fig. 5(a), a large number of shear-bands linking pores were observed in addition to a few cracks. It is considered that the size of the pores is small and the interpore distance is large enough to avoid the stress concentration influence caused by the nearest neighbor pore. In this case the shear-band generation mode is much dominant rather than the crack generation mode. As a result, high flow stress and high plasticity might be observed. On the other hand, as seen in Fig. 5(b), a crack propagation phenomenon through the pore is also observed. In this sample, the size of the pores is large and the distance between the pores is short enough to have the stress concentration influence caused by the nearest neighbor pore. This may be the reason for the generation of local fracture around the pores. It is therefore concluded that the high deformability is observed in the stress-strain curve accompanying significant serrated flow behavior caused by crack propagation.

Successful preparation of $\mathrm{Ni}$-free $\mathrm{Pd}-\mathrm{Pt}-\mathrm{Cu}-\mathrm{P}$ bulk glassy alloys with lower density, lower Young's modulus and higher plasticity indicates the possibility of future applications as biomedical materials.

\section{Summary}

We have investigated the preparation method, thermal stability, and mechanical properties of porous $\mathrm{Pd}_{35} \mathrm{Pt}_{15}$ $\mathrm{Cu}_{30} \mathrm{P}_{20}$ bulk glassy alloy rods. Results obtained are summarized as follows;

(1) Porous $\mathrm{Pd}-\mathrm{Pt}-\mathrm{Cu}-\mathrm{P}$ bulk glassy rods with porosities of 5 and $45 \%$ were successfully produced by holding the alloy melt under $1 \mathrm{MPa}$ hydrogen atmosphere followed by water quenching in reduced hydrogen pressures of 0.9 and $0.1 \mathrm{MPa}$, respectively.

(2) Thermal stability of the porous $\mathrm{Pd}-\mathrm{Pt}-\mathrm{Cu}-\mathrm{P}$ bulk glassy samples is nearly the same as that of the pore-free one.

(3) The porous samples exhibited lower fracture strength, lower Young's modulus and much higher plastic strain. The significantly improved plasticity may be caused by the effects of multi-axis stress and stress concentration around pores.

\section{REFERENCES}

1) L. J. Gibson and M. F. Ashby: Cellular Solids, Structure and Properties, (Pergamon Press, Oxford, 1988).

2) J. Banhart: Prog. Mater. Sci. 46 (2001) 559-632.

3) Porous Materials, Characterization, Production and Application, ed. by Y. Takeuchi, (Fuji Techno System, Tokyo, 1999), (in Japanese).

4) C. E. Wen, M. Mabuchi, Y. Yamada, K. Shimojima, Y. Chino and T. Asahina: Scr. Mater. 45 (2001) 1147-1153.

5) S. Fujibayashi, M. Neo, H. M. Kim, T. Kokubo and T. Nakamura: Biomaterials 25 (2004) 443-450.

6) L. D. Zardiackas, D. E. Parsell, L. D. Dillon, D. W. Mitchell, L. A Nunnery and R. Poggie: J. Biomed. Mater. Res. 58 (2001) 180-187.

7) A. Inoue, A. Kato, T. Zhang, S. G. Kim and T. Masumoto: Mater. Trans., JIM 32 (1991) 609-616.

8) A. Inoue, T. Zhang and T. Masumoto: Mater. Trans., JIM 31 (1990) $425-428$.

9) A. Inoue, T. Zhang and T. Masumoto: Mater. Trans., JIM 36 (1995) 391-398.

10) A. Pecker and W. L. Johnson: Appl. Phys. Lett. 63 (1993) 2342-2344.

11) A. Inoue, W. Zhang, T. Zhang and K. Kurosaka: Mater. Trans. 42 (2001) 1149-1151

12) A. Inoue, N. Nishyama and T. Matsuda: Mater. Trans., JIM 37 (1996) 181-184.

13) A. Inoue, A. Murakami, T. Zhang and A. Takeuchi: Mater. Trans., JIM 38 (1997) 189-196.

14) A. Inoue, B. L. Shen, H. Koshiba, H. Kato and A. R. Yavari: Nature Mater. 2 (2003) 661-663.

15) A. Inoue: Acta Mater. 48 (2000) 279-306.

16) A. Inoue, N. Nishiyama and H. M. Kimura: Mater. Trans., JIM 38 (1997) 179-183.

17) K. Takenaka, T. Wada, N. Nishiyama and A. Inoue: Mater. Trans. 46 (2005) 1720-1724.

18) J. Schroers, C. Veazey and W. L. Johnson: Appl. Phys. Lett. 82 (2003) 370-372.

19) T. Wada and A. Inoue: Mater. Trans. 45 (2004) 2761-2765.

20) T. Wada, A. Inoue and A. L. Greer: Appl. Phys. Lett. 86 (2005) 251907.

21) T. Wada and A. Inoue: Mater. Trans. 44 (2003) 2228-2231.

22) A. H. Brothers, and D. C. Dunand: Adv. Mater. 17 (2005) 484-486.

23) R. Busch: JOM 52 (2000) 39-42.

24) Y. Yokoyama, K. Yamano, K. Fukaura, H. Sunada and A. Inoue: Mater. Trans. 42 (2001) 623-632. 